\title{
Helicobacter pylori infection and markers of gastric cancer risk in Alaska Native persons: A retrospective case-control study
}

\author{
James W Keck MD MPH${ }^{1,2}$, Karen M Miernyk BS ${ }^{2,3}$, Lisa R Bulkow $\mathrm{MS}^{2}$, Janet J Kelly MS MPH ${ }^{3}$, \\ Brian J McMahon MD², Frank Sacco MD, Thomas W Hennessy MD MPH${ }^{2}$, Michael G Bruce MD MPH²
}

\begin{abstract}
JW Keck, KM Miernyk, LR Bulkow, et al. Helicobacter pylori infection and markers of gastric cancer risk in Alaska Native persons: A retrospective case-control study. Can J Gastroenterol Hepatol 2014;28(6):305-310.
\end{abstract}

BACKGROUND: Alaska Native persons experience gastric cancer incidence and mortality rates that are three to four times higher than in the general United States population.

OBJECTIVE: To evaluate pepsinogen I, pepsinogen I/II ratio, antiHelicobacter pylori and cytotoxin-associated gene A (CagA) antibody levels, and blood group for their associations with gastric cancer development in Alaska Native people.

METHODS: The present analysis was a retrospective case-control study that matched gastric cancers reported to the Alaska Native Tumor Registry from 1969 to 2008 to three controls on known demographic risk factors for $\mathrm{H}$ pylori infection, using sera from the Alaska Area Specimen Bank. Conditional logistic regression evaluated associations between serum markers and gastric cancer.

RESULTS: A total of 122 gastric cancer cases were included, with sera predating cancer diagnosis ( mean $=13$ years) and 346 matched controls. One hundred twelve cases $(91.8 \%)$ and 285 controls $(82.4 \%)$ had evidence of previous or ongoing $H$ pylori infection as measured by anti-H pylori antibody levels. Gastric cancer cases had a 2.63-fold increased odds of having positive anti-H pylori antibodies compared with their matched controls $(\mathrm{P}=0.01)$. In a multivariate model, noncardia gastric cancer $(\mathrm{n}=94)$ was associated with anti-H pylori antibodies (adjusted OR 3.92; $\mathrm{P}=0.004$ ) and low pepsinogen I level (adjusted OR $6.04 ; \mathrm{P}=0.04$ ). No association between gastric cancer and blood group, anti-CagA antibodies or pepsinogen I/II ratio was found.

CONCLUSION: Alaska Native people with gastric cancer had increased odds of previous $H$ pylori infection. Low pepsinogen I level may function as a precancer marker for noncardia cancer.

Key Words: Alaska Native; cagA+; Gastric cancer; Helicobacter pylori; Pepsinogen I

Gastric cancer incidence and mortality rates in Alaska Native $\mathbf{J}_{\text {people are high and exceed those of other population groups in }}$ the United States (US). From 2005 to 2007, the mean age-adjusted annual gastric cancer incidence rate was 22.4 per 100,000 Alaska Native people compared with 6.8 per 100,000 in the US white population (1). Gastric cancer is the fifth most frequently diagnosed cancer in Alaska Native people and the third leading cause of cancer mortality. The mortality rate for gastric cancer in Alaska Native people (2003 to 2007) was more than three times higher than the overall US rate (12.7 versus 3.3 per 100,000 population) (2).

One reason for elevated gastric cancer incidence in Alaska Native people may be the high prevalence of Helicobacter pylori infection, shown in other populations to be a risk factor for the development of gastric cancer $(3,4)$. In a survey of $>2000$ samples of blood collected in

\section{L'infection à Helicobacter pylori et les marqueurs de risque de cancer gastrique chez des Autochtones de l'Alaska : une étude cas-témoin rétrospective}

HISTORIQUE : Les Autochtones de l'Alaska présentent une incidence et un taux de mortalité de cancer gastrique de trois à quatre fois plus élevés que l'ensemble de la population des États-Unis.

OBJECTIF : Évaluer le pepsinogène I, le ratio du pepsinogène I/II, le taux d'anticorps contre l'Helicobacter pylori et le gène $\mathrm{A}$ associé à la cytotoxine (CagA) ainsi que le groupe sanguin pour déterminer leur association avec l'apparition du cancer gastrique chez les Autochtones de l'Alaska.

MÉTHODOLOGIE: La présente analyse rétrospective cas-témoins appariait les cancers gastriques déclarés dans le registre des tumeurs des Autochtones de l'Alaska entre 1969 et 2008 à trois contrôles sur les facteurs de risque démographiques connus d'infection à $H$ pylori, au moyen de sérums prélevés dans l'Alaska Area Specimen Bank. Les chercheurs ont utilisé la régression logistique conditionnelle pour évaluer les associations entre les marqueurs sériques et le cancer gastrique.

RÉSULTATS : Au total, 122 cas de cancer gastrique ont été inclus dans l'étude, les sérums ayant été prélevés avant le diagnostic de cancer (moyenne $=13$ ans), de même que 346 sujets-témoins appariés. Cent douze cas $(91,8 \%)$ et 285 sujets-témoins $(82,4 \%)$ présentaient des manifestations d'infection à $H$ pylori antérieure ou en cours d'après la mesure des taux d'anticorps anti-H pylori. Les cas de cancer gastrique risquaient 2,63 fois plus de présenter des anticorps anti- $H$ pylori positifs que les sujets-témoins appariés $(\mathrm{P}=0,01)$. Dans un modèle multivarié, le cancer gastrique ne touchant pas le cardia $(n=94)$ s'associait à des anticorps anti-H pylori $(\mathrm{RC}$ rajusté 3,$92 ; \mathrm{P}=0,004)$ et à un faible taux de pepsinogène I ( $\mathrm{RC}$ rajusté 6,$04 ; \mathrm{P}=0,04)$. Les chercheurs n'ont relevé aucune association entre le cancer gastrique et le groupe sanguin, les anticorps anti-CagA ou le ratio du pepsinogène I/II.

CONCLUSION : Les Autochtones de l'Alaska atteints d'un cancer gastrique étaient plus susceptibles d'avoir déjà été infectés par l'H pylori. Un faible taux de pepsinogène I peut être un marqueur précancéreux de cancer ne touchant pas le cardia.

the 1980 s, $75 \%$ of Alaska Native people were positive for antibodies to $\mathrm{H}$ pylori, indicating past or current infection. Childhood infection was common because $32 \%$ of children $<5$ and $67 \% 5$ to 9 years of age had serological evidence of infection (5). Alaska Native people had a higher prevalence of infection than individuals in similar age groups from multiple populations across Asia, Africa and Latin America (6).

The high burden of gastric cancer in the Alaska Native population calls for new prevention and/or treatment strategies to reduce morbidity and mortality. Because $H$ pylori infection precedes gastric cancer, one possible strategy is to identify individuals with $\mathrm{H}$ pylori and aggressively treat them to decrease $H$ pylori infection and, subsequently, gastric cancer rates. However, the extremely high prevalence of infection, high proportion of isolates demonstrating antimicrobial resistance (7-9) and frequent reinfection (10) make this solution

${ }^{1}$ Epidemic Intelligence Service, Office of Surveillance, Epidemiology, and Laboratory Services, Centers for Disease Control and Prevention, Atlanta, Georgia; ${ }^{2}$ Arctic Investigations Program, Centers for Disease Control and Prevention; ${ }^{3}$ Alaska Native Tribal Health Consortium; ${ }^{4}$ Department of Surgery, Alaska Native Medical Center, Anchorage, Alaska, USA

Correspondence: Dr James W Keck, Arctic Investigations Program, Centers for Disease Control and Prevention, 4055 Tudor Centre Drive, Anchorage, Alaska 99508, USA. Telephone 907-729-3400, e-mail jameswkeck@gmail.com 
impractical. Therefore, we sought associations between gastric cancer and serological markers that could form the basis of screening efforts to more efficiently identify individuals at higher risk for cancer so they may be targeted for early detection and treatment.

Studies involving other populations have investigated serum markers and $\mathrm{H}$ pylori virulence factors for their association with gastric cancer. Researchers have found associations between exposure to $H$ pylori strains expressing the virulence factor cytotoxin-associated gene A (CagA) and gastric cancer $(11,12)$. Low serum pepsinogen I levels and a low pepsinogen I/II ratio, indicative of chronic gastritis (a precursor of gastric cancer) (13), have shown an association with gastric cancer in some studies but not in others $(14,15)$. Finally, some studies have suggested a possible association between blood group A and gastric adenocarcinoma $(16,17)$, although other studies did not demonstrate this association $(18,19)$. No studies have investigated these potential gastric cancer risk markers in Alaska Native people; furthermore, the aforementioned studies examined the association between the markers and patients at the time of their gastric cancer diagnosis. In the present study, our objective was to measure the association between gastric cancer development in Alaska Native people and potential serological cancer markers from samples obtained years before the cancer diagnosis.

\section{METHODS}

\section{Study design}

A retrospective matched case-control study was designed to investigate the association between gastric cancer and various serological and serum markers. Cases included Alaska Native individuals diagnosed with gastric adenocarcinoma in adulthood ( $\geq 18$ years of age) residing in Alaska at the time of diagnosis. Alaska Native people belong to a diverse group of populations indigenous to Alaska. Patients with pathology-confirmed gastric cancer, who had at least one serum specimen in the Alaska Area Specimen Bank collected before their gastric cancer diagnosis, were identified from the Alaska Native Tumor Registry from 1969 through 2008. The Alaska Area Specimen Bank is a collection of $>300,000$ residual biological specimens from 92,000 people participating in various research studies, public health investigations and clinical testing conducted in Alaska since 1963.

Controls were Alaska Native people without known gastric adenocarcinoma (confirmed by review of the Alaska Native Tumor Registry) who resided in Northwest, Southeast, Southwest or Western Alaska, and had at least one serum specimen available from the Alaska Area Specimen Bank during the time period 1969 to 2008. To control for the known demographic risk factors for $\mathrm{H}$ pylori infection within the Alaska Native population (5), controls were matched to cases $(3: 1)$ according to region of residence in Alaska (southwest, southeast, west, northwest), age group (10-year age groupings), sex and date of serum specimen collection $( \pm 10$ years). For cases in which multiple serum samples were available, samples collected $>10$ years before gastric cancer diagnosis were selected because $H$ pylori serological titres have been reported to decline up to 10 years before cancer diagnosis (20). The study protocol received approval from the Centers for Disease Control and Prevention Institutional Review Board and the Alaska Area Institutional Review Board, including a waiver of informed consent because of the use of deidentified, previously collected medical information from the Alaska Native Tumor Registry. Study approval was received from the Bristol Bay Area and the Yukon-Kuskokwim Health Corporations (southwest), Maniilaq Association (northwest), Norton Sound Health Corporation (west) and the SouthEast Alaska Regional Health Consortium (southeast).

\section{Data abstraction}

The Alaska Native Tumor Registry (www.anthc.org/chs/epicenter/), established in 1973, was used to obtain information about the gastric cancers. The Alaska Native Tumor Registry is a full member of the National Cancer Institute Surveillance, Epidemiology, and End Results (SEER) program, and provides comprehensive cancer surveillance of approximately 127,000 Alaska Native people residing in Alaska (21). Additional patient data were obtained from death certificates and RPMS, the health information system used by the Alaska Tribal Health System. The national SEER database (22), a collection of 17 regional registries that provide population-based surveillance for approximately $28 \%$ of the US population (http://seer.cancer.gov/), was accessed to obtain national gastric cancer data. SEER*Stat version 6.6.2 (National Cancer Institute, USA) was used to calculate frequencies from the national database (excluding cases from the Alaska Native Tumor Registry) for reported gastric cancers that occurred from 1973 to 2007.

\section{Laboratory testing}

Commercial kits were used to test samples for anti-H pylori antibodies (Helicobacter pylori IgA/IgG ELISA; Biohit, Finland), anti-CagA antibodies (Helicobacter pylori p120 [CagA] ELISA; ravo Diagnostika, Germany), pepsinogen I (Pepsinogen I ELISA, Biohit), pepsinogen II (Pepsinogen II ELISA, Biohit) and blood grouping (Affirmagen pooled reagent red blood cells; Ortho Clinical Diagnostics, USA). The manufacturer's test procedures and analysis instructions were followed for all tests. The manufacturer's cut-off values were used for normal versus abnormal levels of pepsinogen I $(25 \mu \mathrm{g} / \mathrm{L})$ and the pepsinogen I/II ratio (2.5). An abnormally low value for either indicates advanced corpus atrophy. Also followed was manufacturer guidance to determine anti-H pylori antibody positivity ( $\geq 30$ enzyme immune units [EIU]) and anti-CagA antibody positivity ( $>7.5$ units; 5 to 7.5 units indeterminate).

\section{Sample size calculation and statistical analysis}

Using previously reported estimates for $\mathrm{H}$ pylori and CagA seropositivity in Alaska Native people, sample sizes were calculated under a variety of assumptions. To detect an $\mathrm{OR} \geq 2$ at a $95 \%$ significance level $(\mathrm{P}<0.05)$ with $80 \%$ power and 1:3 case-control matching, the calculations produced sample sizes of 107 to 163 cases and 321 to 489 controls (data not shown). Descriptive analyses of case, control and gastric cancer characteristics were undertaken, which are reported as frequencies and percentages; $z, \chi^{2}$ and paired $t$ tests were used to evaluate differences in proportions and their distributions and paired serological data, as appropriate. The analysis excluded pepsinogen values from five grossly hemolyzed serum samples and anti- $\mathrm{H}$ pylori antibody enzyme immunoassay values $>1500$ (but not the positive test result) due to the instability of the test kit in that range ( 14 samples). To preserve matching, associations between serological markers and gastric cancer development were checked using univariate and multivariate conditional logistic regression. When more than one serum sample per case was available, the earlier-collected sample was used for modelling. Purposeful backward stepwise regression was used for multivariate models and initially included variables with $\mathrm{P} \leq 0.2$. In addition, subgroup analyses were performed and restricted to: gastric cancers not located in the cardia region of the stomach (noncardia) because of the reported lack of association between $H$ pylori infection and gastric cancers arising from the cardia of the stomach $(3,4,23)$; cases with serum samples collected $\geq 10$ years before gastric cancer diagnosis due to the reported decline of $\mathrm{H}$ pylori antibodies leading up to gastric cancer diagnosis (20); gastric cancer cases diagnosed before 50 years of age (approximately the first age quartile in the sample) because of genetic differences in early onset cancers $(24,25)$; and anti-H pylori antibody-positive cases and controls. All reported $\mathrm{P}$ values are twosided; $\mathrm{P}<0.05$ was considered to be statistically significant. Stata version 10 (StataCorp, USA) was used to perform statistical analyses.

\section{RESULTS}

Participant characteristics

Of the 206 reported cases of gastric adenocarcinoma with at least one available serum sample over the 40-year study period, permission from the regional tribal health organizations was granted to include $129(62.6 \%)$ of these cases and initially matched to 377 controls. From this group were 


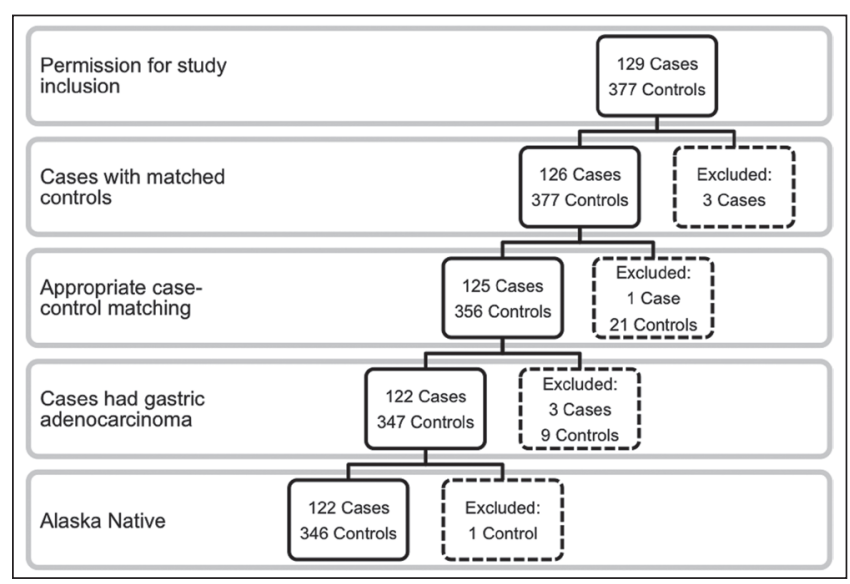

Figure 1) Reasons for exclusion of seven cases and 31 controls from a matched case-control study of serum markers and gastric cancer in 129 Alaska Native people diagnosed with cancer from 1969 to 2008

excluded: three cases for lack of matched controls; one case and 21 controls for sex mismatch; three cases with non-adenocarcinoma histologies (two epithelial and one squamous cell) and their nine matched controls; and one control who identified as non-Native. One hundred twenty-two individuals with gastric cancer and 346 matched controls were retained for analysis (Figure 1). Two serum samples were available for $38(31.1 \%)$ cases; the other cases and all of the controls had one sample. Samples obtained from cases predated gastric cancer diagnosis by a mean of 13 years (interquartile range nine to 18 years). Of the gastric cancer group, $73.0 \%$ ( 89 of 122 ) were male, the group's mean $( \pm \mathrm{SD})$ age at the time of serum sample collection was $45.2 \pm 16.1$ years, mean age at time of diagnosis was $58.6 \pm 15.7$ years and the proportion $<50$ years of age was $29.5 \%$ (36 of 122 ). The control group was $72.8 \%$ ( 252 of 346 ) male and had a mean age of $41.2 \pm 17.6$ years at serum collection. Almost all cases and controls, $92.6 \%$ and $92.8 \%$, respectively, identified as Eskimo, and $93.4 \%$ and $94.2 \%$, respectively, lived in rural western Alaska communities.

\section{Serum markers and gastric cancer}

It was found that $91.8 \%$ (112 of 122 ) of the gastric cancer patients and $82.4 \%$ ( 285 of 346 ) of the control group had evidence of previous or ongoing $\mathrm{H}$ pylori exposure indicated by elevated anti-H pylori antibody levels (Table 1). A greater percentage of cases $(95.1 \%[\mathrm{n}=116])$ and controls (93.1\% [ $\mathrm{n}=322]$ ) had evidence of $\mathrm{H}$ pylori exposure as measured by anti-CagA immunoglobulin $\mathrm{G}(\mathrm{IgG})$. All of the cases $(\mathrm{n}=122)$ and $342(98.8 \%)$ of the controls demonstrated evidence of previous or ongoing $\mathrm{H}$ pylori exposure when combining these two serological markers of $H$ pylori infection. Low pepsinogen I level was uncommon, with $4.1 \%$ (five of 121 ) of cases and $2.1 \%$ (seven of 342 ) of controls recording serum pepsinogen I levels $<25 \mu \mathrm{g} / \mathrm{L}$. Equally uncommon was a low pepsinogen I/II ratio: $5.0 \%$ (six of 121 ) of case and 2.9\% (10 of 342 ) of control samples had a calculated ratio $<2.5$.

Individuals who developed gastric cancer had a 2.59-fold higher odds of positive $\mathrm{H}$ pylori serology than their matched controls ( $\mathrm{P}=0.013$; [95\% CI 1.22 to 5.50$]$ ), the only significant univariate association (Table 2). Also calculated were matched ORs using a pepsinogen threshold of $75 \mu \mathrm{g} / \mathrm{L}$ and a pepsinogen I/II ratio of 10 ; however these analyses did not result in any additional statistically significant associations (data not shown). In the multivariate analysis, which retained variables with $\mathrm{P}<0.25$ (positive $H$ pylori serology and pepsinogen I), only the presence of $H$ pylori antibody was significantly associated with gastric cancer (OR 2.63 [95\% CI 1.21 to 5.62]; $\mathrm{P}=0.01$ ) (Table 2).

Analysis of gastric cancer patient subgroups revealed associations between gastric cancer and $\mathrm{H}$ pylori exposure and low pepsinogen I levels, as shown in Table 2. A multivariate model of noncardia gastric
TABLE 1

Demographic and sera characteristics of Alaska Native gastric cancer cases and controls

\begin{tabular}{|c|c|c|}
\hline Characteristic & $\begin{array}{c}\text { Case } \\
(n=122)\end{array}$ & $\begin{array}{l}\text { Control } \\
(n=346)\end{array}$ \\
\hline Male sex & $89(73.0)$ & $252(72.8)$ \\
\hline \multicolumn{3}{|l|}{ Region (Alaska) of residence } \\
\hline Northwest & $28(23.0)$ & $78(22.5)$ \\
\hline Southeast & $8(6.6)$ & $20(5.8)$ \\
\hline Southwest & $59(48.4)$ & $172(49.7)$ \\
\hline West & $27(22.1)$ & $76(22.0)$ \\
\hline Age at specimen collection*, years & $45.2 \pm 16.1^{\dagger}$ & $41.2 \pm 17.6$ \\
\hline $\begin{array}{l}\text { Specimen collection time before diagnosis, } \\
\text { years* }\end{array}$ & $13.0 \pm 7.0$ & na \\
\hline Age at gastric cancer diagnosis, years & $58.6 \pm 15.7$ & na \\
\hline 25th percentile & 47 & na \\
\hline 50th percentile & 60 & na \\
\hline 75th percentile & 71 & na \\
\hline \multicolumn{3}{|l|}{ Blood group } \\
\hline A & $51(41.8)$ & $136(39.3)$ \\
\hline$A B$ & $8(6.6)$ & $34(9.8)$ \\
\hline B & $12(9.8)$ & $42(12.1)$ \\
\hline $\mathrm{O}$ & $51(41.8)$ & $134(38.7)$ \\
\hline Helicobacter pylori positive ${ }^{\ddagger}$ & $112(91.8)^{\dagger}$ & $285(82.4)$ \\
\hline CagA positive§ & $116(95.1)$ & $322(93.1)$ \\
\hline CagA intermediate $§$ & & $7(2.0)$ \\
\hline H pylori or CagA positive ${ }^{ \pm \S}$ & $122(100.0)$ & $342(98.8)$ \\
\hline Pepsinogen I lowा & $5(4.1)$ & $7(2.0)$ \\
\hline Pepsinogen $1 / I I$ low $^{\star *}$ & $6(5.0)$ & $10(2.9)$ \\
\hline
\end{tabular}

Data presented as $n(\%)$ or mean $\pm S D$. *If two specimens collected, earlier specimen collection age used; ${ }^{\dagger} P<0.05 ;{ }^{\ddagger}$ Anti-H pylori immunoglobulin (Ig) $G / I g A$ $\geq 30$ enzyme immune units; $\$$ Cytotoxin-associated gene $A$ (CagA) IgG: $<5$ units (negative), 5 to 7.5 units (indeterminate), $>7.5$ units (positive); ${ }^{\top} P e p s i n o g e n$ $<25 \mu \mathrm{g} / \mathrm{L}$ (one case and four control sample values excluded due to hemolyzed sera); ${ }^{* *}$ Pepsinogen I/II ratio <2.5. na Not applicable

cancer cases $(n=94)$ showed associations with anti-H pylori antibodies (adjusted $\mathrm{OR}[\mathrm{aOR}] 3.92 ; \mathrm{P}=0.004)$ and low pepsinogen I levels (aOR 6.04; $\mathrm{P}=0.04$ ). Individuals diagnosed with gastric cancer before 50 years of age $(n=36)$ had a stronger association with anti-H pylori antibodies (aOR 7.96; $\mathrm{P}=0.047$ ) than cases diagnosed in individuals $\geq 50$ years of age $(n=86 ;$ aOR $1.88 ; P=0.14)$. Gastric cancer patients with serum specimens collected $\geq 10$ years before their cancer diagnosis $(n=86)$ had an association with anti-H pylori antibodies ( $a \mathrm{OR} 3.20 ; \mathrm{P}=0.013$ ), while cases with specimens from $<10$ years before diagnosis did not $(\mathrm{n}=36$; aOR 0.13; $\mathrm{P}=0.86)$. Also investigated were cases and controls positive for anti-H pylori antibodies, which found a nonsignificant association between gastric cancer and antecedent low pepsinogen I level ( $\mathrm{aOR} 4.48 ; \mathrm{P}=0.08$ ). To assess for temporal changes in specimen values and gastric cancer associations, serum specimens collected before and after 1980 were grouped and analyzed. The association of gastric cancer with anti-H pylori and anti-CagA antibodies, pepsinogen I, and the pepsinogen I/II ratio between the two time periods were similar and not significantly different (data not shown). Additionally, the mean values for these serum markers were not statistically different across the two time periods (data not shown).

\section{Paired sera}

For 38 of the gastric cancer cases, two separate prediagnosis serum samples were collected a mean of 7.2 years apart (interquartile range four to nine years) (Table 3 ). Of the measured serum markers, only anti-H pylori antibody levels changed significantly between the earlier and later samples (mean increase $=31.4 \pm 90.0$ EIU; $\mathrm{P}=0.04$ ), increasing an average of 5.9 EIU per year. Paired specimen antibody level 
TABLE 2

Gastric cancer predictors according to case group

\begin{tabular}{|c|c|c|c|c|c|c|c|c|}
\hline \multirow[b]{2}{*}{ Univariate analysis } & \multicolumn{2}{|c|}{$\begin{array}{l}\text { All cases } \\
(n=122)\end{array}$} & \multicolumn{2}{|c|}{$\begin{array}{c}\text { Cases with specimens } \geq 10 \\
\text { years before diagnosis }(n=86)\end{array}$} & \multicolumn{2}{|c|}{$\begin{array}{c}\text { Noncardia } \\
\text { cases }(n=94)\end{array}$} & \multicolumn{2}{|c|}{$\begin{array}{l}\text { Helicobacter pylori-positive } \\
\text { cases and controls }(n=112)\end{array}$} \\
\hline & OR & $\mathbf{P}$ & OR & $\mathbf{P}$ & OR & $\mathbf{P}$ & OR & $\mathbf{P}$ \\
\hline $\bar{H}$ pylori positive* & 2.59 & 0.01 & 3.39 & 0.01 & 3.49 & 0.01 & na & na \\
\hline CagA intermediate and positive ${ }^{\dagger}$ & 0.98 & 0.97 & 1.32 & 0.63 & 0.75 & 0.56 & 0.83 & 0.72 \\
\hline CagA positive ${ }^{\dagger}$ & 1.40 & 0.47 & 1.95 & 0.23 & 1.10 & 0.84 & 1.28 & 0.62 \\
\hline 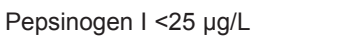 & 1.97 & 0.27 & 2.50 & 0.20 & 3.48 & 0.11 & 4.48 & 0.08 \\
\hline Pepsinogen $\mathrm{I} / \mathrm{II}$ ratio $<2.5$ & 1.72 & 0.33 & 2.33 & 0.19 & 2.30 & 0.25 & 2.22 & 0.20 \\
\hline Blood group A versus others & 1.11 & 0.62 & 1.27 & 0.36 & 1.15 & 0.57 & 1.00 & 1.00 \\
\hline \multicolumn{9}{|l|}{ Multivariate analysis ${ }^{\ddagger}$} \\
\hline H pylori positive & 2.63 & 0.01 & 3.32 & 0.01 & 3.92 & 0.004 & na & na \\
\hline Pepsinogen I, low (<25 ㅆg/L) & 2.56 & 0.15 & 2.98 & 0.15 & 6.04 & 0.04 & 4.48 & 0.08 \\
\hline
\end{tabular}

Bolded values indicate statistical significance. *Anti-H pylori immunoglobulin (lg) $\mathrm{G} / \mathrm{lgA} \geq 30$ enzyme immune units; ${ }^{+}$Cytotoxin-associated gene $A$ (CagA) IgG: $<5$ units (negative), 5 to 7.5 units (indeterminate), >7.5 units (positive); $¥$ Only variables significant at $P<0.2$ were retained in the multivariate model. na Not applicable

TABLE 3

Characteristics of paired sera taken before gastric cancer diagnosis

\begin{tabular}{|c|c|c|c|c|}
\hline \multirow[b]{3}{*}{ Characteristic } & \multicolumn{4}{|c|}{ Specimen } \\
\hline & \multirow{2}{*}{$\begin{array}{l}\text { Earlier } \\
(n=38)\end{array}$} & \multirow{2}{*}{$\begin{array}{l}\text { Later } \\
(\mathrm{n}=38)\end{array}$} & \multicolumn{2}{|c|}{ Paired, change $(\Delta)$} \\
\hline & & & Mean $\Delta$ & Mean $\Delta /$ year \\
\hline Anti-Helicobacter pylori antibody*, enzyme immune units & $109.6 \pm 77.5$ & $141.7 \pm 121.7$ & $31.4^{\dagger}$ & 5.9 \\
\hline Pepsinogen I, $\mu \mathrm{g} / \mathrm{L}$ & $138.6 \pm 65.9$ & $140.8 \pm 91.2$ & 2.2 & 0.5 \\
\hline Pepsinogen I/II ratio & $8.9 \pm 3.9$ & $8.9 \pm 5.4$ & 0.01 & 0.1 \\
\hline Age at serum collection, years & $49.3 \pm 15.9$ & $56.6 \pm 15.3$ & 7.2 & \\
\hline
\end{tabular}

Data presented as mean $\pm S D$ unless otherwise indicated. *One sample censored from each case group due to instability of laboratory test at values $>1500$ enzyme immune units. ${ }^{\dagger} P<0.05$ for paired $t$ test between earlier and later specimens

changes varied widely in direction and magnitude, decaying $(\mathrm{n}=15)$ or rising $(n=23)$ from -38.1 EIU to 63.5 EIU per year. Anti-H pylori antibody levels and their relation to time before cancer diagnosis from all sera in the cancer group $(n=141)$ were further evaluated and no trend was found $(\mathrm{P}=0.53)$.

\section{Gastric cancers}

The most frequently occurring histological type of gastric cancer in the sample, as classified by International Classification of Diseases for Oncology, Third Edition (ICD-O-3) codes (26), was adenocarcinoma, not otherwise specified $(\mathrm{n}=81[66.4 \%])$ followed by signet ring cell $(n=19$ [15.6\%]) and adenocarcinoma, intestinal type $(n=8$ [6.6\%]; Table 4). The distribution of histological cancer types in the sample was not statistically different from the national SEER data $\left(\chi^{2}=9.91\right.$; $\mathrm{df}=12 ; \mathrm{P}=0.62)$. Most gastric cancers in the study were moderately differentiated $(n=35[28.7 \%])$ or poorly differentiated $(n=55[45.1 \%])$ histologically, which was similar to national data $\left(\chi^{2}=4.24 ; \mathrm{df}=4\right.$; $\mathrm{P}=0.38)$. The gastric adenocarcinomas occurring in this sample were in a variety of locations in the stomach: $28(23 \%)$ in the cardia; $69(56.6 \%)$ in the body (fundus, greater and lesser curvatures, and antrum); six (4.9\%) in the pylorus; four (3.3\%) in overlapping regions; and $15(12.3 \%)$ at unspecified locations. This distribution of reported gastric cancer sites was different from national reports $\left(\chi^{2}=59.94 ; \mathrm{df}=8 ; \mathrm{P}<0.001\right)$, with a greater proportion of Alaska Native cancers occurring in the greater and lesser curvatures, and fewer occurring in the body and overlapping regions, compared with national data. Summary staging information (27) was available for 101 (82.8\%) of the cancers, and $21(20.8 \%)$ of the staged cancers were localized, 44 (43.6\%) were regional and $36(35.6 \%)$ were distant, which was similar to the national data $\left(\chi^{2}=4.89 ; \mathrm{df}=3\right.$; $\mathrm{P}=0.18$ ).

\section{DISCUSSION}

For the first time, we report an association between the presence of serum anti-H pylori antibodies and the development of gastric cancer in Alaska Native people. This association was larger among people with noncardia gastric cancer and individuals $<50$ years of age. The larger OR found in younger individuals likely arises from control $\mathrm{H}$ pylori seropositivity increasing with age, which diminishes the association apparent in the older age group. Unlike results reported by most previous studies $(11,12)$, exposure to CagA-positive $H$ pylori strains, as measured by anti-CagA antibody levels, did not appear to increase an individual's risk for gastric cancer in our study population. The near-ubiquitous presence of anti-CagA antibodies (95.1\% each of cases and controls), which was significantly higher than reported in other studies $(28,29)$, may have masked any true association between this virulence factor and gastric carcinogenesis. However, other studies have also found no association between infection with CagA-positive $H$ pylori strains and gastric cancer (30), particularly in populations in which $\mathrm{H}$ pylori prevalence more closely mirrors that of rural Alaska (31). The high proportion of participants seropositive for CagA is likely due to prevalent $H$ pylori infection and the relative antigenicity of the CagA protein, resulting in persistent CagA antibodies even after clearance of $\mathrm{H}$ pylori infection and $\mathrm{H}$ pylori IgG antibodies (32).

Few studies have evaluated pepsinogen levels and ratios before gastric cancer diagnosis to determine the predictive or screening value of these markers for gastric cancer. Most studies examined these serum markers in individuals at the time of their gastric cancer diagnosis $(14,15,33,34)$. We found that low pepsinogen I level $(<25 \mu \mathrm{g} / \mathrm{L})$ was significantly associated with the development of noncardia gastric cancer when controlling for $\mathrm{H}$ pylori seropositivity. However, only a minority $(4.1 \%)$ of people who subsequently developed gastric cancer had low pepsinogen levels, suggesting that few cancers would be detected using this marker. Our findings contrast with those of Parsonnet et al (35), who found antecedent low pepsinogen I $(<50 \mu \mathrm{g} / \mathrm{L})$ in $35.2 \%$ (45 of 128) of individuals who developed gastric cancer and reported a significant association between low pepsinogen I level and subsequent cancer in individuals with evidence of $H$ pylori infection. A low pepsinogen $\mathrm{I} / \mathrm{II}$ ratio $(<2.5)$ was not associated with an increased risk for developing gastric cancer in the Alaska Native study population. The disparate frequencies of low pepsinogen I between the present study 
and other published studies may relate to variations in laboratory methods, particularly duration of sample storage, and is unlikely a reflection of differing gastric cancer pathophysiologies given the similarity of our sample cases to the SEER national sample.

The descriptive pathology of our study sample of Alaska Native gastric cancers was similar to that reported by SEER registries from other US populations. Summary staging information from our study population and from a recent report on cancer in Alaska Natives (36) suggests that gastric cancers in Alaska Native people were diagnosed at a stage similar to those reported in the national SEER database. This finding implies that delayed diagnosis due to access to health care (availability and utilization) is not the main explanation for increased Alaska Native gastric cancer mortality. Histology and histological grade were also similar between the two groups, indicating that Alaska Native people did not experience different or more aggressive tumours than other US populations. The main difference between the two groups was in the recorded sites of the gastric adenocarcinomas, although the differences were mainly in the specific location within the body of the stomach (body, lesser and greater curvatures), which is likely due to variance in surgical reporting and not cancer location. The similarity in descriptive gastric cancer pathologies and stage at diagnosis between the national and study samples suggests that the reason for a higher gastric cancer mortality rate in Alaska Native people is due to elevated cancer incidence in this population.

In the 38 individuals with gastric cancer and available paired serum specimens, we saw a significant increase in anti-H pylori EIU levels from earlier to later specimens, although antibody level changes were heterogeneous, with some individuals experiencing a decline in antibody levels. Our finding counters the report by Tulinius et al (20) describing a decline in $\mathrm{H}$ pylori antibody levels approaching cancer diagnosis. The increasing antibody levels apparent in our study may have resulted from the high prevalence of $H$ pylori infection in this population, leading to re-exposure to $\mathrm{H}$ pylori and priming of the immune system. Focused exploration of anti-H pylori antibody levels and their temporal relation to gastric cancer diagnosis may further clarify the association.

We aimed to test sera obtained before a diagnosis of gastric cancer. However, because of the retrospective nature of the study, we did not perform endoscopy on individuals to confirm their lack of gastric cancer at the time of serum collection, meaning that we may have included serum samples from individuals (cases) with undiagnosed gastric cancer. However, this scenario is unlikely because $70 \%$ of samples predated diagnosis by 10 years and $>90 \%$ predated diagnosis by at least five years, during which time the likelihood of identifying gastric cancer would have been high. Additionally, our subanalysis was restricted to cases with samples predating diagnosis by at least 10 years had similar findings to the primary analysis (Table 2). Another challenge was the multiple changes made to summary staging and ICD-O-3 code definitions during the 40 years of study data. To correct for this, SEER provides updated coding and staging manuals on a regular basis and recodes data within SEER*Stat to provide uniformity across the multiple years of cancer registry data. Finally, the sample of Alaska Native people with gastric adenocarcinomas may not represent all Alaska Native people because the study population resided primarily in rural areas.

Evidence of $\mathrm{H}$ pylori infection was widespread in our study population. Although we demonstrated an association between previous infection and subsequent gastric cancer, the utility of $H$ pylori seropositivity screening to predict gastric cancer in a population with such elevated rates of infection and reinfection is low. While noncardia gastric cancer cases showed an association with previous low pepsinogen I levels, the extremely low sensitivity of this potential screening test for predicting gastric cancer minimizes its clinical utility in this population. Because of the disproportionate burden of gastric cancer in the Alaska Native population, we will continue to examine potential markers of gastric cancer risk and to evaluate potential screening strategies to identify individuals at risk. As a next step,
TABLE 4

Comparison of Alaska Native and nationally reported gastric adenocarcinoma characteristics

\begin{tabular}{|c|c|c|}
\hline & $\begin{array}{c}\text { Alaska Native } \\
\quad(n=122)\end{array}$ & $\begin{array}{c}\text { SEER } \\
(n=94,251)\end{array}$ \\
\hline \multicolumn{3}{|l|}{ Histology* } \\
\hline Adenocarcinoma, not otherwise specified & $81(66.4)$ & $60,883(64.6)$ \\
\hline Linitis plastica & $4(3.3)$ & $2316(2.5)$ \\
\hline Adenocarcinoma, intestinal type & $8(6.6)$ & $5511(5.8)$ \\
\hline Carcinoma, diffuse type & $3(2.5)$ & $2352(2.5)$ \\
\hline Adenocarcinoma in adenomatous polyp & $0(0.0)$ & $640(0.7)$ \\
\hline Tubular adenocarcinoma & $1(0.8)$ & $477(0.5)$ \\
\hline Carcinoid tumour, malignant & $0(0.0)$ & $2147(2.3)$ \\
\hline Adenocarcinoma with mixed subtypes & $0(0.0)$ & $503(0.5)$ \\
\hline Papillary adenocarcinoma & $2(1.6)$ & $520(0.6)$ \\
\hline Mucinous adenocarcinoma & $3(2.5)$ & $2219(2.4)$ \\
\hline Mucin-producing adenocarcinoma & $1(0.8)$ & $1877(2.0)$ \\
\hline Signet ring cell adenocarcinoma & $19(15.6)$ & $13,744(14.6)$ \\
\hline Other adenocarcinomas & $0(0.0)$ & $1062(1.1)$ \\
\hline \multicolumn{3}{|l|}{ Histological grade } \\
\hline Well differentiated & $6(4.9)$ & $4598(4.9)$ \\
\hline Moderately differentiated & $35(28.7)$ & $20,129(21.4)$ \\
\hline Poorly differentiated & $55(45.1)$ & $46,594(49.4)$ \\
\hline Undifferentiated & $2(1.6)$ & $2514(2.7)$ \\
\hline Unknown & $24(19.7)$ & $20,416(21.7)$ \\
\hline \multicolumn{3}{|l|}{$\mathrm{Site}^{\dagger}$} \\
\hline Cardia, not otherwise specified & $28(23.0)$ & $22,480(23.9)$ \\
\hline Fundus & $7(5.7)$ & $3966(4.2)$ \\
\hline Body $\ddagger$ & $0(0.0)$ & $7338(7.8)$ \\
\hline Gastric antrum & $19(15.6)$ & $18,368(19.5)$ \\
\hline Pylorus & $6(4.9)$ & $3402(3.6)$ \\
\hline Lesser curvature ${ }^{\ddagger}$ & $30(24.6)$ & $8915(9.5)$ \\
\hline Greater curvature $\ddagger$ & $13(10.7)$ & $4001(4.2)$ \\
\hline Overlapping§ & $4(3.3)$ & $8729(9.3)$ \\
\hline Stomach, not otherwise specified & $15(12.3)$ & $17,052(18.1)$ \\
\hline \multicolumn{3}{|l|}{ Summary staging" } \\
\hline Localized & $21(19.1)$ & $17,835(23.3)$ \\
\hline Regional§ & $44(40.0)$ & $23,653(30.9)$ \\
\hline Distant & $36(32.7)$ & $26,432(34.5)$ \\
\hline Unstaged & $9(8.2)$ & 8729 (11.4) \\
\hline
\end{tabular}

Data presented as $n$ (\%). *Histology classification according to International Classification of Diseases for Oncology, Third Edition (ICD-O-3) codes (26). ICD-O-3 cancer types reported that were $\geq 0.05 \%$ of the national total; ${ }^{\dagger}$ Site according to ICD-O-3 topography codes; $¥ P<0.001$ for $z$ test of proportions between the Alaska Native and national Surveillance Epidemiology and End Results (SEER) groups; $\S_{P}<0.05$ for $z$ test of proportions between the Alaska Native and national SEER groups; "Summary staging according to SEER definition (27). Includes only gastric cases diagnosed in 1984 and later because summary staging not available before 1984 in the Alaska Native Tumor Registry

we will characterize $H$ pylori strains circulating in the Alaska Native population to search for genotypes associated with gastric cancer and study how host characteristics predispose individuals to gastric cancer.

ACKNOWLEDGEMENTS: The authors thank Marcella Harker-Jones for her help with blood typing and the Bristol Bay Area Health Corporation, the Yukon-Kuskokwim Health Corporation, the Maniilaq Association, the Norton Sound Health Corporation, and the SouthEast Alaska Regional Health Consortium for their participation in this study. 


\section{REFERENCES}

1. National Cancer Institute, Surveillance Research Program, Cancer Statistics Branch. Surveillance, Epidemiology, and End Results (SEER) Program SEER*Stat Database: Incidence - SEER 13 Regs Research Data (Katrina/Rita Population Adjustment) - Linked to County Attributes - Total U.S., 1969-2007 Counties, 2010.

2. National Cancer Institute, Surveillance Research Program, Cancer Statistics Branch. Surveillance, Epidemiology, and End Results (SEER) Program SEER*Stat Database: Mortality - All COD, Aggregated With State (Katrina/Rita Population Adjustment), Total U.S. (1990-2007), 2010.

3. Parsonnet J, Friedman GD, Vandersteen DP, et al. Helicobacter pylori infection and the risk of gastric carcinoma. N Engl J Med 1991;325:1127-31.

4. Helicobacter and Cancer Collaborative Group. Gastric cancer and Helicobacter pylori: A combined analysis of 12 case control studies nested within prospective cohorts. Gut 2001;49:347-53.

5. Parkinson AJ, Gold BD, Bulkow L, et al. High prevalence of Helicobacter pylori in the Alaska native population and association with low serum ferritin levels in young adults. Clin Diagn Lab Immunol 2000;7:885-8.

6. Bardhan PK. Epidemiological features of Helicobacter pylori infection in developing countries. Clin Infect Dis 1997;25:973-8.

7. Bruce MG, Bruden DL, McMahon BJ, et al. Alaska sentinel surveillance for antimicrobial resistance in Helicobacter pylori isolates from Alaska Native persons, 1999-2003.

Helicobacter 2006;11:581-8.

8. Carothers JJ, Bruce MG, Hennessy TW, et al. The relationship between previous fluoroquinolone use and levofloxacin resistance in Helicobacter pylori infection. Clin Infect Dis 2007;44:e5-8.

9. McMahon BJ, Hennessy TW, Bensler JM, et al. The relationship among previous antimicrobial use, antimicrobial resistance, and treatment outcomes for Helicobacter pylori infections. Ann Intern Med 2003;139:463-9.

10. McMahon BJ, Bruce MG, Hennessy TW, et al. Reinfection after successful eradication of Helicobacter pylori: A 2-year prospective study in Alaska Natives. Aliment Pharmacol Ther 2006;23:1215-23.

11. Blaser MJ, Perez-Perez GI, Kleanthous H, et al. Infection with Helicobacter pylori strains possessing $\mathrm{CagA}$ is associated with an increased risk of developing adenocarcinoma of the stomach. Cancer Res 1995;55:2111-5.

12. Parsonnet J, Friedman GD, Orentreich N, Vogelman H. Risk for gastric cancer in people with CagA positive or CagA negative Helicobacter pylori infection. Gut 1997;40:297-301.

13. Correa P, Houghton J. Carcinogenesis of Helicobacter pylori. Gastroenterology 2007;133:659-72.

14. Kodoi A, Yoshihara M, Sumii K, Haruma K, Kajiyama G. Serum pepsinogen in screening for gastric cancer. J Gastroenterol 1995;30:452-60.

15. Yoshihara M, Hiyama T, Yoshida S, et al. Reduction in gastric cancer mortality by screening based on serum pepsinogen concentration: A case-control study. Scand J Gastroenterol 2007;42:760-4.

16. Aird I, Bentall HH, Roberts JA. A Relationship between cancer of stomach and the ABO blood groups. Br Med J 1953;1:3.

17. You WC, Ma JL, Liu W, et al. Blood type and family cancer history in relation to precancerous gastric lesions. Int J Epidemiol 2000;29:405-7.

18. Pocard M, Panis Y, Valleur P, Sarazin D. No correlation between $H$. pylori and blood groups in gastric cancer. Gastroenterology $1998 ; 114: 1$

19. Umlauft F, Keeffe EB, Offner F, et al. Helicobacter pylori infection and blood group antigens: Lack of clinical association.

Am J Gastroenterol 1996;91:2135-8.
20. Tulinius H, Ogmundsdottir HM, Kristinsson KG, et al. Helicobacter pylori antibodies and gastric cancer in Iceland - the decline in IgG antibody level is a risk factor. APMIS 2001;109:835-41.

21. U.S. Census Bureau, Population Division. Table 5. Estimates of the Resident Population by Race Alone or in Combination and Hispanic Origin for the United States and States: July 1, 2009 (SC-EST2009-5), 2010.

22. National Cancer Institute, Surveillance Research Program, Cancer Statistics Branch. Surveillance, Epidemiology, and End Results (SEER) Program SEER*Stat Database. Incidence - SEER 17 Regs Research Data + Hurricane Katrina Impacted Louisiana Cases, Nov 2009 Sub (1973-2007 varying) - Linked to County Attributes Total U.S. Counties, 1969-2007 2010.

23. Kamangar F, Dawsey SM, Blaser MJ, et al. Opposing risks of gastric cardia and noncardia gastric adenocarcinomas associated with Helicobacter pylori seropositivity. J Natl Cancer Inst 2006;98:1445-52.

24. Carvalho R, Milne AN, van Rees BP, et al. Early-onset gastric carcinomas display molecular characteristics distinct from gastric carcinomas occurring at a later age. J Pathol 2004;204:75-83.

25. Milne AN, Sitarz R, Carvalho R, Carneiro F, Offerhaus GJ. Early onset gastric cancer: On the road to unraveling gastric carcinogenesis. Curr Mol Med 2007;7:15-28.

26. Fritz A, Percy C, Jack A, et al. International Classification of Diseases for Oncology, 3rd edn. Geneva: World Health Organization, 2000.

27. Young JL Jr, Roffers SD, Ries LAG, Fritz AG, eds HA. SEER Summary Staging Manual - 2000: Codes and Coding Instructions, Bethesda: National Cancer Institute, NIH, 2001.

28. Ekstrom AM, Held M, Hansson LE, Engstrand L, Nyren O. Helicobacter pylori in gastric cancer established by CagA immunoblot as a marker of past infection. Gastroenterology 2001;121:784-91

29. Wong BC, Lam SK, Ching CK, et al. Seroprevalence of cytotoxinassociated gene A positive Helicobacter pylori strains in Changle, an area with very high prevalence of gastric cancer in south China. Aliment Pharmacol Ther 1999;13:1295-302.

30. Yamaoka Y, Kodama T, Kashima K, Graham DY. Antibody against Helicobacter pylori CagA and VacA and the risk for gastric cancer. J Clin Pathol 1999;52:215-8.

31. Mitchell HM, Hazell SL, Li YY, Hu PJ. Serological response to specific Helicobacter pylori antigens: Antibody against CagA antigen is not predictive of gastric cancer in a developing country. Am J Gastroenterol 1996;91:1785-8.

32. Ye W, Held M, Enroth H, Kraaz W, Engstrand L, Nyrén O. Histology and culture results among subjects with antibodies to CagA but no evidence of Helicobacter pylori infection with IgG ELISA. Scand J Gastroenterol. 2005;40:312-8.

33. So JB, Yeoh KG, Moochala S, et al. Serum pepsinogen levels in gastric cancer patients and their relationship with Helicobacter pylori infection: A prospective study. Gastric Cancer 2002;5:228-32.

34. Yoshihara M, Sumii K, Haruma K, et al. Correlation of ratio of serum pepsinogen I and II with prevalence of gastric cancer and adenoma in Japanese subjects. Am J Gastroenterol 1998;93:1090-6.

35. Parsonnet J, Samloff IM, Nelson LM, Orentreich N, Vogelman JH, Friedman GD. Helicobacter pylori, pepsinogen, and risk for gastric adenocarcinoma. Cancer Epidemiol Biomarkers Prev 1993;2:461-6.

36. Lanier AP, Kelly JJ, Maxwell J, McEvoy T, Homan C. Cancer in Alaska Natives 1969-2003: 35-Year Report. Alaska Native Tribal Health Consortium, 2006. 


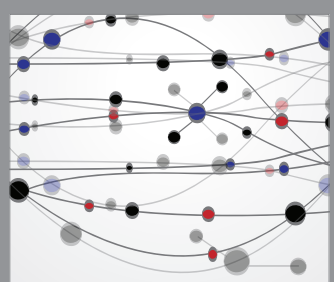

The Scientific World Journal
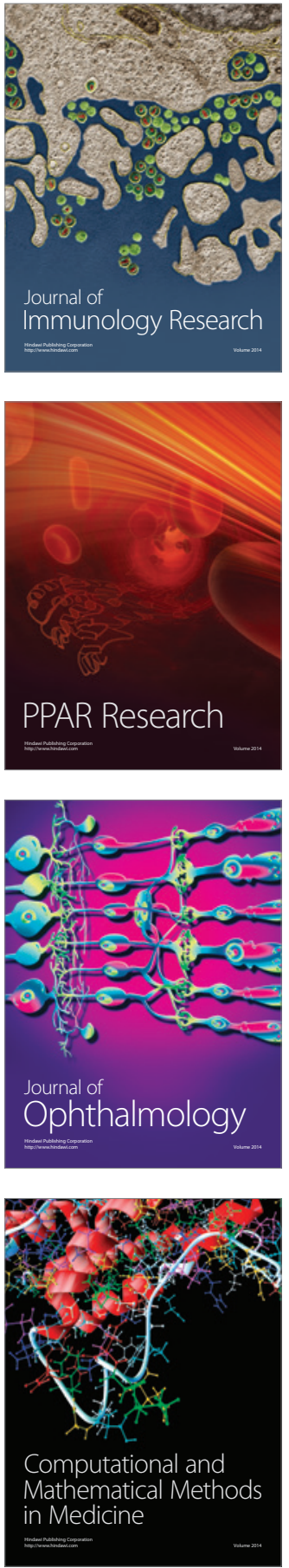

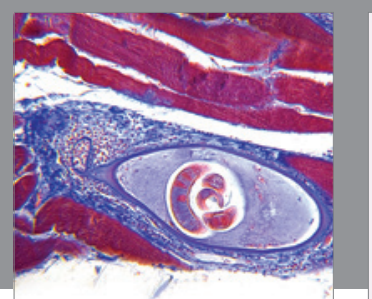

Gastroenterology Research and Practice

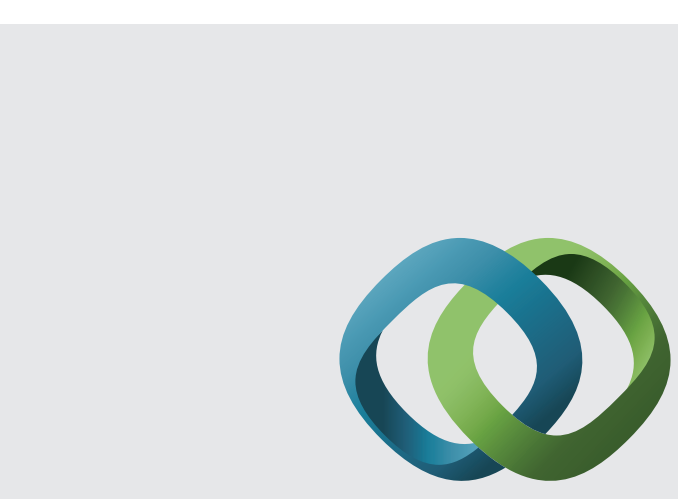

\section{Hindawi}

Submit your manuscripts at

http://www.hindawi.com
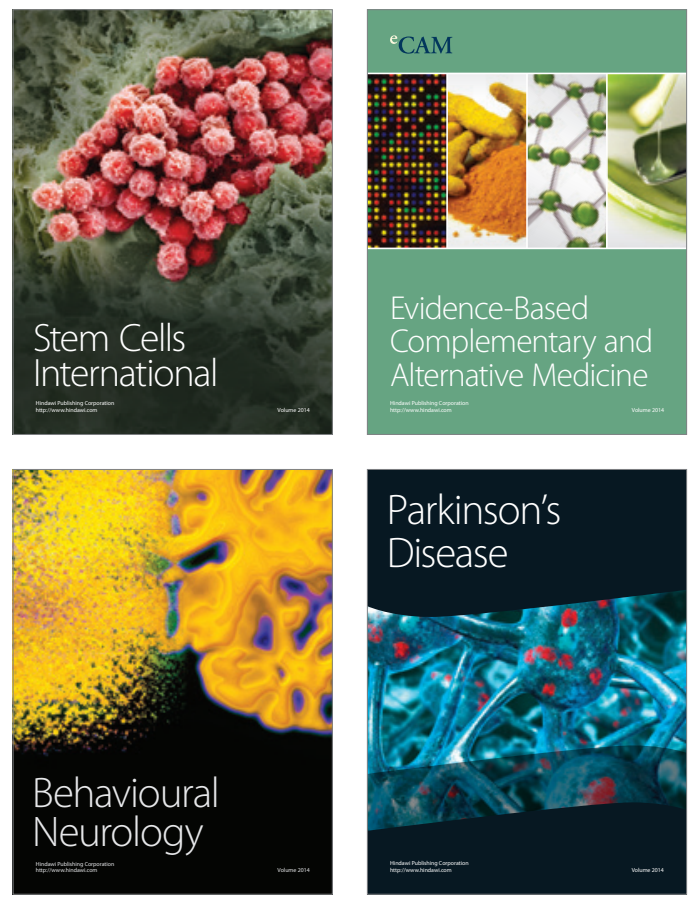
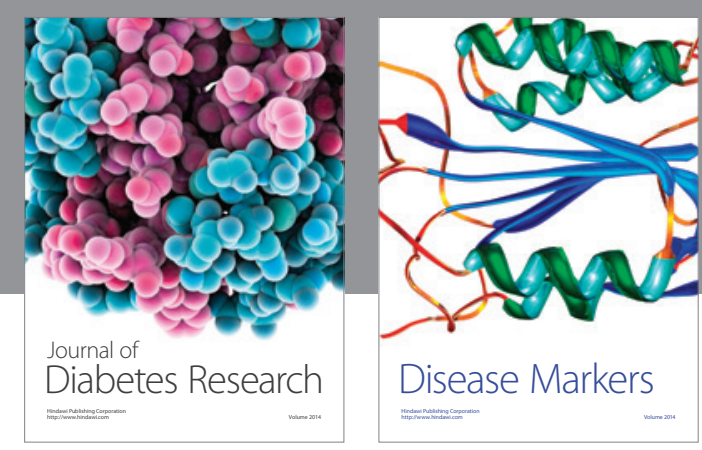

Disease Markers
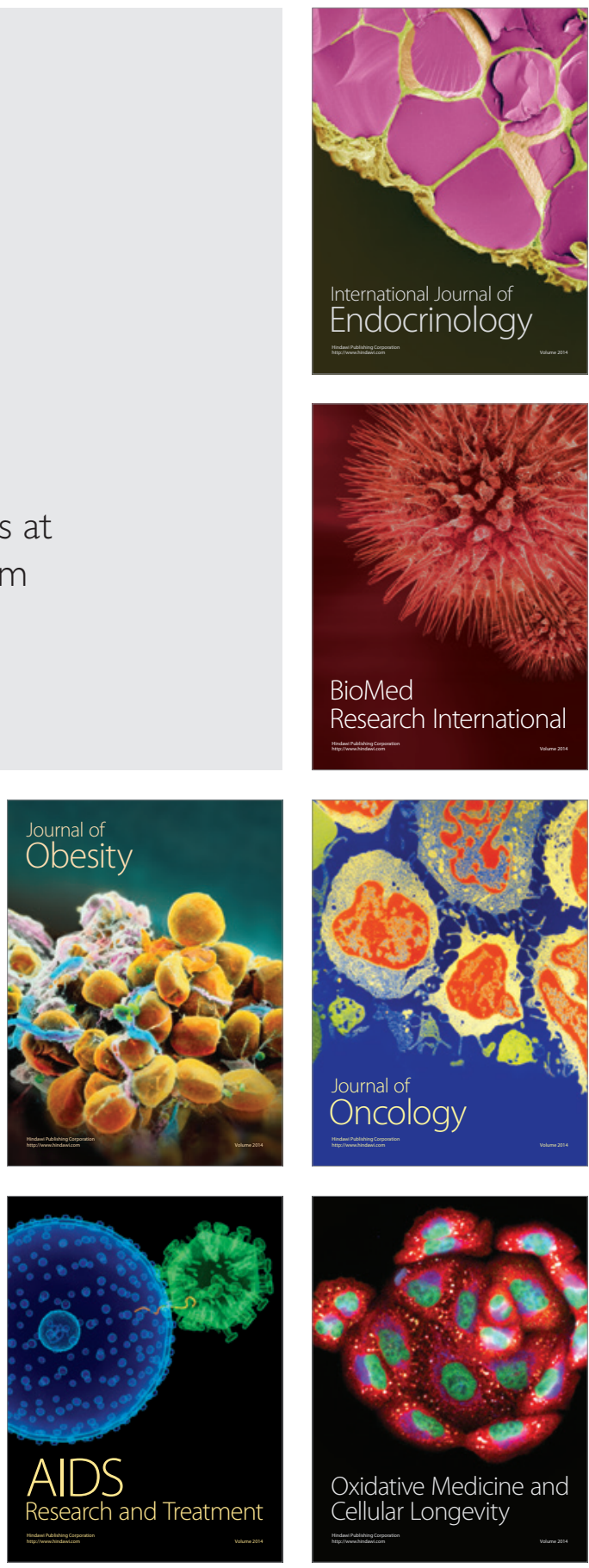